\title{
Displaced Persons in North-Eastern Nigeria: Causes, Effects and the Role of Social Workers
}

\author{
Aminu Zubairu Surajo*, Abdulkadir Shitu Umar, Jamilu Musa, Mohammed Jamilu Haruna \\ Department of Social Development, School of Rural Technology and Entrepreneurship Development Rano, Kano State \\ Polytechnic, Nigeria
}

Received September 5, 2019; Revised October 12, 2019; Accepted October 17, 2019

Copyright $\odot 2020$ by authors, all rights reserved. The authors agree that this article remains permanently open access under the terms of the Creative Commons Attribution License 4.0 International License

\begin{abstract}
The displacement of people within their own countries is currently a common international and national phenomenon. Migration of internally displaced persons in the north-eastern part of Nigeria is caused by internal armed conflict, particularly caused by the Boko Haram insurgency. The internally displaced people are living in highly vulnerable conditions. They suffer discriminations, faced emotional trauma, experience significant deprivation and impoverishment. The paper focuses on the role of the social workers in assisting the internally displaced persons of the northeast who are ravaged by the operation of insurgents. The present study aims at examining the causes and effects of the displacement of persons in the study area. A mixed method of data was employed. Therefore, two hypotheses and four research questions were formulated to guide the study. A total of 278 respondents was utilised for the study and stratified random sampling was used to select the respondents. In addition to that, six respondents were engaged in an interview and purposive sampling was used to select the interviewers. The instruments used in the study are self designed questionnaire tagged the Internally Displaced Persons Questionnaire (IDPQ) and the interview protocol. The questionnaire has a reliability coefficient of 0.82 . The t-test at 0.05 level of significance was used in testing the null hypotheses. While thematic analyses were used for the interview. The findings of the study show that there is no significant difference in the manner of people's displacement due to Boko Haram insurgency. However, there is a significant relationship between internally displaced persons and their vulnerability. Similarly, the result revealed that injustice, security lapses, weak and inefficient governance, illiteracy as well as unemployment are the causes of the displacement. Consequently, the effects of the displacement include lack of peace and stability, family disintegration, alienation, loss of economic opportunities, breakdown of cultural identity, loosening of social and family structure, interruption of children's schooling and increased poverty.
\end{abstract}

Keywords Internally Displaced Persons, Social Workers, Displacement

\section{Introduction}

The social work profession has been committed to the defence and promotion of human rights (Ekpe and Mamah, 1997). Social workers in Nigeria focus their attention on working with the most vulnerable in the country, regardless of ethnicity, language, gender, religious belief, ideology, age, physical ability or status (Okoye, 2013). The most vulnerable people in the country now are the internally displaced persons. The plight of the internally displaced persons in recent years in the northeast has become a formidable problem in the country. This is associated with the insurgency of the radical terrorist group in Nigeria known as Boko Haram that engulf the entire north-eastern states of Borno and Yobe States (Falaju, 2005).

The activities of Boko Haram have left many people dead and many others homeless, causing people to flee their abode in search of safety and security. Internal Displacement Monitoring Center (2016) noted that there are about two million, one hundred and fifty-two thousand $(2,152,000)$ internally displaced persons in Nigeria as at 31 December 2015 (Oladeji, 2015; Mohammed, 2017). The United Nations describes Internally Displaced Persons (IDP) as individuals or groups of individuals forced to run away from their usual residences in order to avoid the harmful effects of armed conflict, terrorism, situations of generalized violence, abuse of human rights, natural or man-made disasters, and who have not crossed an internally recognized state border (UN, 2006).”

In Nigeria, a humanitarian crisis such as internal displacement results from a combination of factors, including terrorist activities, deplorable environmental conditions and ethnic and religious violence. By far the 
activities of the radical Islamist armed group Boko Haram proved to be the singular most important factor in the increasing number of IDPs in the country (Rider, 2012; ICRC, 2016;). The insurgency of Boko Haram affects the polity, security and economy of Nigeria but was brutal, highly destructive and directly focused on northern territories in Nigeria, particularly the north-eastern states of the country (Rider, 2012).

Boko Haram's fierce attacks triggered the displacement of the majority of citizens who presently occupy many of the IDP camps across the country. It is important to note that out of the victims of the most violent attacks, women, girls and children have been the most affected, with the abduction and forced marriage of girls, which is a defining feature of the Boko Haram insurgency. It is estimated that over $50 \%$ of the IDP population are children; nearly half of the people impacted by the conflict are under the age of 18 years and they are mostly at risk of violations of their rights (Abdulazeez, 2016).

Therefore, it is against this background that the paper will examine the role of the social workers in assisting the internally displaced persons of the northeast as well as to investigate the causes and the effects of persons' displacement. The role of the government in finding a lasting solution to the problem was also analysed.

\section{Objectives}

The study has the following objectives:

- To analyse the causes of the displacement of persons in the north-east.

- To investigate the effects of the displacement of persons in the north-east.

- To examine the role of the social workers in assisting the internally displaced persons in the north-east.

\section{Research Questions}

The fundamental questions that require investigation are:

- What are the causes of the displacement of persons in the north-east?

- What the effects of the displacement of persons in the north-east?

- What is the role of the social workers in assisting the internally displaced persons in the north-east?

\section{Hypothesis}

The two null hypotheses were formulated to guide the study as follows:

$\mathrm{HO}_{1}$ : There is no significant relationship between internally displaced persons and their vulnerability.

$\mathbf{H O}_{2}$ : There is no significant difference in the manner of people’s displacement due to Boko Haram insurgency.

\section{Theoretical Explanation}

Human needs theory holds the belief that an individual is in collective pursuit of needs and values which forms the core of their social and international behaviour. Human needs are a powerful source of explanation of human behaviour and social interaction. All individuals have needs, they strive to satisfy, either by using the system 'acting on the fringes' or acting as a reformist or a revolutionary. Human needs theory was popularized in the works of Abraham Maslow, John Burton, Marshall Rosenberg and Manfred Max-Neef (Coate \& Rosati, 1988).

To properly resettle into the society, the needs of internally displaced persons must be adequately met. These needs according to Abraham Maslow are basic and essential for the survival and well-being of these groups of persons.

\section{Literature Review}

\subsection{The Insurgency and Internally Displaced Persons in Nigeria}

The number of Internally Displaced Persons (IDPs) in Nigeria has increased rapidly some years back, largely due to the activities insurgencies in the north-eastern part of the country, where a steady recurrence of violent attacks since 2009 has left well over two million people displaced within and across the borders to neighbouring countries, especially over the past three years (Cohen and Den, 2016; Mohammed, 2017).

The turbulent acts of insurgency, particularly those that emerged from the Boko Haram group of extremists, challenged the Nigerian state in the early 2000s without success and re-emerged with the leadership of Mohammed Yusuf, who proselytized in Borno until 2009 (Cohen \& Den, 20016). The group has become openly violent since 2009, adopting terrorist tactics, including targeted assassinations, suicide bombings, hostage taking, and outright attacks on places of worships, markets and social gatherings in some local communities and villages in the region.

The Internal Displacement Monitoring Centre (2016) suggested the figure of Internally Displaced Persons in Borno state to be one million four hundred and thirty four thousand, one hundred and fourty nine $(1,434,149)$, the highest in Nigeria. Millions of people became homeless when the terrorist group Boko Haram emerged in the State in the last seven years. The National Emergency Management Agency (2017) said Internally Displaced Persons (IDPs) camps in Borno State remained 32 in spite of the recent return of some persons to liberated communities. Out of the 32 camps, 16 of them were located 
in Maiduguri, while the remaining 16 were in local government areas of the state.

Displaced people in the camp collect clothes, food and medicines. The displaced people are defenceless so they need support. The government cannot cover all spheres and solve all problems of the displaced persons, therefore social workers need to help in order to support them. Unfortunately, the camps cannot always be protected, cases of extremists' attacks on camps are not uncommon. But the government is working to provide military protection to internally displaced persons in the camps.

\subsection{Social Work with Displaced Persons}

The International Federation of Social Workers (IFSW) concerns about the displacement of people. This coincides with the United Nations Commission on Human Right, which in its resolutions 73 of 1992 designated a special rapporteur of internal displacement in response to growing international concern about the large number of internally displaced persons in the world and their needs for assistance and protection (IFSW, 1994).

Social workers must be sensitive to the conditions that increase the displaced person's vulnerability. These include discriminations, emotional trauma, significant deprivation and impoverishment of the displaced population. Therefore, the social workers working with the displaced persons have a role to play in providing sustainability, overcoming dependence on humanitarian assistance, regaining productive capacity, rebuilding socio-cultural and community structure as well as personal and collective ability to contribute proactively to national and regional development (Dhemba, 2012).

Similarly, social workers play an important role in addressing emotional needs of the displaced persons in all interventions, sustaining the displaced people during their mourning process, helping them to regain peace of mind, self-confidence and confidence in others. To be conscious of their right, and the obligatory implementation inherent in these rights is all necessary components of psychological support to the displaced persons within the larger concept of mental health, psychological service as well as development assistance to the most vulnerable, especially women and children (Ekpe and Mamah, 1997).

Social workers should be able to convey information on the right of the displaced persons and services available to them to access organizations and mobilization processes and to act as trainers and motivators for social participation aimed at developing democratic relations. In addition to that, social workers promote mechanism that enabled displaced persons to participate in the planning of their own future as well as in local, regional and national political action. Furthermore, social workers serve as an instrument used in advising government on best practices in dealing with displacement (Hall, 1990).

\section{Methodology}

The paper utilized mixed method of data collection as a research design. Therefore, the data were sourced through questionnaires which were administered to the internally displaced persons in their camps in Borno and Yobe State. Similarly, the research was supplemented by a face to face interview with the internally displaced persons. The questionnaires comprise of the demographic information such as sex and age of the respondents. The questionnaires also included both closed and open ended questions. The close ended questions were expressed in either "Yes or No" format while the open ended questions allowed the respondents to freely express themselves by writing down what they feel about the displacement of persons in Borno and Yobe State. The researchers employed the service of the research assistants to help the uneducated respondents in answering the questionnaires. Similarly, the interview administered, gave the researchers the opportunity to have face to face discussions with the respondents which comprises both the displaced persons and the social workers. In addition to that the researchers ask follow-up questions that are not contained in the interview protocol.

The questionnaires and interview protocol are the instruments used for data collection. The questionnaire was developed by the researchers and tagged Internally Displaced Persons Questionnaire (IDPQ). It was divided into two sections; the first section contains the demographic information of the respondents, while the second section contains questions that bother with the research topic. Equally, the interview protocol comprises of the demographic information of the respondents as well as the questions designed for the internally displaced persons. Additionally, the interviews conducted were semi-structured and were conducted with six respondents. The researchers employed purposive sampling as a technique for selecting respondents for the interview in order to provide the desired information by knowing the minds, opinions, attitudes and feelings of the respondents. However, it is essential in a survey research to determine a sample size and deal with a non-response bias. Therefore, the common goal is to collect data representative of a population. The ideal population of the study consisted of five hundred (500) internally displaced persons. The sample size for this study were drawn from the ideal population and the research tolerate 5\% margin error, thus 217 samples was used for the study based on the sample size determination of Krejcie and Morgan (1970). The stratified random sampling technique was used for the administration of the questionnaires and all the questionnaires were returned by the respondents. The instrument was validated by the experts in the area of measurement and evaluation to ensure content validity. Meanwhile the reliability of the instrument was based on the Cronbach Alpha which produced reliability co-efficient of 0.80 . The result showed that the instrument was good 
enough to be used. The data collected from the respondent questionnaires were analysed using t-test analysis. While for the interview, the data collected were analysed using thematic analysis.

\section{Results}

The results of the study are based on the data collected from the two instruments used in this research (i.e. Questionnaires and interview protocol).

The demographic information of the respondents included the sex and age of the respondents. The sex of the respondents was presented in tabular form as follows:

Table 1. Frequency and percentage distribution of respondents according to gender

\begin{tabular}{|c|c|c|}
\hline Gender & Frequency & Percentage (\%) \\
\hline Male & 49 & 23 \\
\hline Female & 168 & 77 \\
\hline Total & 217 & 100 \\
\hline
\end{tabular}

Source: Field Work 2019

Table 1 above indicates that of the two hundred and seventeen (217) respondents, 49 (23\%) of them are male and $168(77 \%)$ of them are female. This show that the majority of the displaced people in the IDP camps are females.

Table 2 indicates that out of the two hundred and seventeen (217) respondents, 25 (12\%) of them are aged between 1 to 10 years-old and 42 (19\%) respondents belong to the age group of 11 to 20 years-old. Similarly, 69 (32\%) respondents age between 21 to 30 years-old. 55 (25\%) respondents belong to the age group of 31 to 40 years-old and 20 (9\%) respondents age between 41 to 50 years-old. The remaining 6 (3\%) respondents belong to the age group of 51 to 60 years-old. Therefore, it can be concluded that the majority of the respondents are between the ages of 21 to 30 years-old. This indicates that the majority of the displaced persons in the IDP camps are teenagers that require careful handling in terms of security, character training and education.

However, the two null hypotheses were tested using the t-test analysis below:

Hypothesis $1\left(\mathbf{H O}_{1}\right)$ : There is no significant relationship between internally displaced persons and their vulnerability.

Table 2. Frequency and percentage distribution of respondents according to age

\begin{tabular}{|c|c|c|}
\hline Age & Frequency & Percentage (\%) \\
\hline $1-10$ years & 25 & 12 \\
\hline $11-20$ years & 42 & 19 \\
\hline $21-30$ years & 69 & 32 \\
$31-40$ years & 55 & 25 \\
$41-50$ years & 20 & 09 \\
$51-60$ years & 06 & 03 \\
\hline Total & 217 & 100 \\
\hline
\end{tabular}

Source: Field Work 2019

The result in table 3 shows that the calculated t-test value of 8.110 is greater than the critical t-test value of 0.145 at 0.05 level of confidence. This implies that the null hypothesis which stated that there is no significant relationship between internally displaced persons and vulnerability, is rejected.

Hypothesis $2\left(\mathbf{H O}_{2}\right)$ : There is no significant difference in the manner of people's displacement due to Boko Haram insurgency.

Table 3. Showing the t-test analysis between internally displaced persons and their vulnerability.

\begin{tabular}{|c|c|c|c|c|c|c|c|}
\hline Variables & $\mathrm{N}$ & $\mathrm{X}$ & $\mathrm{SD}$ & $\mathrm{DF}$ & t.cal. & t.crit. & Decision \\
\cline { 1 - 6 } Internally Displaced Persons & 142 & 3.98 & 0.79 & \multirow{2}{*}{215} & \multirow{2}{*}{8.110} & \multirow{2}{*}{0.145} & Significant \\
\cline { 1 - 7 } & 75 & 2.80 & 1.35 & & & & \\
\hline
\end{tabular}

Table 4. Showing the t-test analysis between the manner of people’s displacement and Boko Haram insurgency.

\begin{tabular}{|c|c|c|c|c|c|c|c|}
\hline Variables & $\mathrm{N}$ & $\mathrm{X}$ & $\mathrm{SD}$ & $\mathrm{DF}$ & t.cal. & t.crit. & Decision \\
\cline { 1 - 6 } Manner of people's displacement & 109 & 1.92 & 0.97 & \multirow{2}{*}{76} & \multirow{2}{*}{0.117} & \multirow{2}{*}{0.218} & Not Significant \\
\hline Boko Haram insurgency & 108 & 1.90 & 0.96 & & \\
\hline
\end{tabular}


The data in table 4 above indicate that the calculated t-test value of 0.117 is less than the critical t-test value of 0.218 at 0.05 level of confidence. This implies that the null hypothesis which stated that there is no significant difference in the manner of people's displacement due to Boko Haram insurgency, is retained.

In addition to that, the results of the interview gathered from six respondents were presented and analysed. The views of the respondents were examined based on the following subheadings:

\subsection{The Causes of the Displacement in the North-East}

The respondents gave their opinions on the causes and consequences of the displacement. The themes that emerged from the respondent's explanation for the causes of the displacement includes: injustice, security lapses, weak and inefficient governance, illiteracy and unemployment. Therefore, on injustice; one of the respondent mention that they were treated very unfairly by the insurgents and were not given their expected rights as full citizens of the country. She further stated that:

We were affected by the Boko Haram insurgency. People, especially from Borno and Yobe State experienced maltreatment and a violation of their rights. The majority of us were killed or maimed, while our children, particularly young girls are raped, abused and battered.

On the issue of security lapses, this phenomenon occurred when the government failed to provide security to its citizens which lead to their displacement. One of the respondents has this to share:

During the insurgency, the government temporarily fails in its arrangements for the safety of its citizens despite efforts to protect them. The military runs short of weapons and logistics, the rate of bombing continues, arms and ammunition continue to circulate at the hands of insurgents and unscrupulous people in our society, anxiety and lack of trust increase among people. This condition is unbearable.

Weak and inefficient governance are one of the causes of displacement. Respondents believe that weak governance brings about unaccountable bureaucracies, unenforced or unjust legal systems, abuse of executive power and widespread corruption. This condition encouraged insurgency, which caused a large number of displaced persons in the society.

The study revealed that illiteracy among the generality of the population in the north-eastern part of Nigeria brought about insurgency, which subsequently triggered internally displaced person's conditions. One of the respondents expressed his concerns as follows:

Majority of Boko Haram insurgents lack religious and western education. They were misguided by their leaders to fight for their selfish interest.

Similarly, unemployment among the teeming youths, particularly those from Borno and Yobe States instigate youths to join Boko Haram insurgency and carry arms to fight against the legitimate government of Nigeria. One of the respondents has this to share:

When youths have no jobs, they are deprived of the capacity to earn steady income and cannot live a socially productive existence. And because of the absence of decent jobs, many youths in the north-eastern part of the country are compelled to live indecent lives. Therefore, they become an easy target of being members of Boko Haram.

\subsection{The Effects of the Displacement in the North-East}

Based on the perception of the respondents, the effect of the displacement includes lack of peace and stability, family disintegration, loss of economic opportunities, breakdown of cultural identity, loosening of social and family structure, interruption of children's schooling and increased poverty. Therefore, lack of peace and stability is one of the major effect of the people's displacement according to respondents. One of the respondents narrated his experience as follows:

The insurgency has both physical and psychological effects on the displaced persons like us. Our health has extremely been affected. We get frightened at any moment. We live in an uncertain situation about our relatives since we are unaware whether they are dead or alive. The insurgency has seriously affected us.

The study exposed that families have continued to disintegrate due to the insurgency of Boko Haram. One of respondents confirms that:

The insurgency was a terrible and horrendous situation I ever experienced in my life. All my family members were killed, with the exception of me and my wife. I run for my life, but my wife was spared by the insurgents (since they don't normally kill women). My house was completely burnt and some of my relatives are out there hiding in the forest. I lost my sense of belonging because of the problem. Life has not been comfortable because I am not living a life of my own anymore, my family is totally disintegrated.

Loss of economic opportunities is the inability to have chances to do work that somebody is willing to pay for. According to some respondents, the majority of the displaced persons do not have the wherewithal to engage in any financial or profitable ventures that can help them earn a living. One of the respondents expressed his concerns as follows:

The insurgency was life-taking as it saw an end of various lives and properties. It reduced great destinies and cut short the economic opportunities of the people. The trauma of the insurgency is a phenomenon that will live with me forever.

In the same direction, the study also discovered that 
breakdown of cultural identity comprises of absence of belongings to a group. The majority of the internally displaced persons experienced collapse of cultural identity as a result of the Boko Haram insurgency. Similarly, internally displaced persons lose their social and family structure due to the death of family members and the breakdown of the family system. One of the respondents, described his experience:

The structure of our family is devastated. Everybody is scattered as a result of Boko Haram attack and we cannot trace their location. In fact, we are not aware whether they alive or dead.

Furthermore, the study indicated that due to Boko Haram insurgency and subsequent breakdown of the affected family, their children stop schooling. One of the respondents expressed his opinion:

All our schools in the area, both government and private close down. The Majority of private school proprietors are not the indigenes of the area, they close permanently and run away for their safety.

However, some respondents believe that one of the major effect of people displacement is increased poverty of the internally displaced person. Poverty deprived them of the proper opportunities and adequate means of subsistence in order to have healthy and satisfying life. These include inadequate income, limited household possession, hunger and malnutrition due to insurgency. One of the respondents described her experience:

We are very poor; we lack everything in life. All our belongings are completely destroyed by the insurgents. We don't know where to stay, we don't have food to eat and money to spend for essential commodities. Thanks to National Emergency Management Agency (NEMA) for assisting us in the IDP camp.

\subsection{The Role of Social Workers in Supporting Internally Displaced Persons}

This section comprises the opinion of social workers in providing social support to the displaced persons in the camps. The respondents gave their opinions on the role of social workers in supporting internally displaced persons particularly in the northeast. The themes that emerged from the respondent's explanation on the role of social workers includes: addressing the mental health issues through counselling, partner with NGO's to provide relief materials, engaged in public awareness, advocate for resources and education, organize peace and reconciliation programmes.

However, addressing the mental health issues of internally displaced persons is one of the major roles of social workers in the northeast. Since majority of them suffer from depression and anxiety due to the conflict. The social workers counsel the IDP's in their camp as narrated by one of the respondents:

Social workers play the key roles in addressing the mental health issues of internally displaced persons in a variety of settings. Social workers engaged in counsellorship, impart the best practices for addressing the specific needs of these vulnerable people. The internally displaced persons are struggling with the trauma and loss as a result of Boko Haram Insurgency

On the issue of partnering with NGO's in the region, social workers collaborate to deliver relief materials to the affected persons as confirm by one of the respondents:

Internally displaced persons are struggling with socioeconomic issues, therefore social workers partner with NGO'S in providing relief materials to the affected people in the area of food supply and health care service delivery.

In the same direction, the study also revealed that social workers, particularly in Borno and Yobe States engaged in public awareness on the need to go back to their community for proper resettlement after the effort of the Nigerian armed forces in neutralizing the attack of the civilian population by the insurgents. One of the respondents has this to share:

Social workers engaged in providing public awareness for the internally displaced persons by assisting them to return to their communities for resettlement especially now the menace of Boko Haram has reduced significantly as a result of military campaign against them.

The study revealed that social workers advocate for resources and education to internally displaced persons and their children, mainly from the government and international donor agencies. One of the respondents share his views:

Social workers have an ethical mandate to address social and economic justice issues. Therefore, social workers advocate for resources and education to internally displaced persons and their children.

Furthermore, the study revealed that in an attempt to bring a durable cease fire in the ongoing insurgency campaign by members of the Boko Haram, social workers establish peace and reconciliation programmes in the city of Maiduguri and its surrounding villages. This attempt was not successful as confirm by one of the respondents:

The indigenous social workers attempted on several occasions to plan and organize peace and reconciliation programmes with the representatives of Boko Haram insurgents for the benefit of internally displaced persons in particular and security of the country in general.

\section{Discussions}

One of the findings of this study is that there was a significant relationship between internally displaced persons and their vulnerability. The result supports the 
assertion of Okpe (2008) which stated that the internally displaced persons in Nigeria are susceptible and experience greater risk in their camps, they lack adequate food supplies, they lack financial and medical support and unfortunately, the camps cannot always be protected. Cases of extremists' attacks on camps are not uncommon. According to Christensen and Niels (2009) displaced people are highly vulnerable. They suffer from discrimination, experience significant deprivation and are frequently impoverished. They are marginalised within their own society and they faced the emotional trauma of their uprooting experience. Displaced people turn into excluded people, they also suffer from grief relating to dead or missing family members and in extreme cases, resort to delinquency and begging in order to survive.

Another finding of this study revealed that there was no significant difference in the manner of people's displacement due to Boko Haram insurgency. This coincides with the findings of Deng (1995) who argues that there is a worldwide tendency for an increase in displaced populations alongside the upsurge of social, political and cultural conflicts. This is in large measure the result of accelerated technological development of arms, which has turned the civil population into the main victims of Boko Haram conflicts.

The findings of the study indicate that the causes of the displacement originate from injustice, security lapses, weak and inefficient governance, illiteracy and unemployment of the poor citizens. These findings relate to the findings of Korn (1988) who contend that the rationale behind the displacement is multifaceted and it resulted from human right violation to security breaches and insurgencies. There are socioeconomic and political imbalances, injustices and inequities, as well as insensitivity to the plight of their citizens. Government partiality and its lackadaisical attitudes, joblessness of the people are the most important causes of the displacement. The rights of the affected people are relegated and they suffer in all ramifications. Similarly, according to Kellenberger (2009) reported that the causes of displacement are manifold and complex. The causes are those that have triggered or contributed to armed conflict or situations of violence. Poverty, the effects of climate change, scarcity of resources, political instability, and weak governance and justice systems may all be catalysts for conflict-induced displacement.

Furthermore, the findings of the study highlighted the consequences of the displacement which include lack of peace and stability, family disintegration, loss of economic opportunities, breakdown of cultural identity, loosening of social and family structure, interruption of children's schooling and increased poverty. These factors often hamper the end of displacement and make the task of rebuilding lives and restoring the livelihoods of people affected by displacement all the more difficult. This corresponds with the findings of Abdulazeez (2016) who found out that internal displacement poses perhaps one of the most daunting humanitarian challenges of today. The impact on many millions of displaced men, women and children is hard, if not impossible to measure.

According to Mohammed (2017) the internally displaced person left their homes and properties destroyed, looted or burnt down during the violent conflict. The majority of them flee to neighbouring communities that are safe, usually taking refuge in temporary shelters such as schools, public buildings and places of worship among others; having been deprived of their homes and sometimes their land and livelihoods. Hence, lacking access to the necessities of life, such as food, water and shelter. Similarly, Oladeji (2015) observe that the internally Displaced Persons in Nigeria faced insecurity and all forms of exploitation and abuse, including rape, having camped in congested shelters, isolated, insecure or inhospitable areas. IDPs are also largely separated from their families especially, unaccompanied children and teenagers, the elderly and sick, the handicapped and pregnant women, whose special needs and privacy are not attended to, due to fragmented and uncoordinated humanitarian response to the needs of IDPs. They also faced the absence of access to justice, in relation to cases of human rights violations such as discrimination against ethnic and religious minorities, sexual violence, and deprivation of means of livelihood.

The findings of the study discovered that social workers play a greater role of in supporting internally displaced persons in the north-eastern part of Nigeria affected by the insurgency of Boko Haram. They engaged in counselling with the internally displaced persons in order to tackle their mental health issues. This coincides with the findings of Dhemba (2012) who argues that social workers provide counselling services to the majority of internally displaced persons in their camps, who are struggling with the emotional trauma as well as new stressors which impact individual and family lives, such as behavioural problems in children, depression and anxiety, domestic violence, and parental relationships. Similarly, social workers are in partnership with the non-governmental organizations in providing relief materials to the affected people. This relates to the findings of Ekpe, and Mamah (1997) who observed that within the global context, most international social workers are found working with non-governmental organizations (NGOs) in order to plan and implement the assistance programme with the aim of addressing the welfare issues of the displaced population.

In the same direction, social workers engaged in public awareness, advocate for resources and education, organize peace and reconciliation programmes. This corresponds with the findings of Ahmad (2009) who found out that social workers have major roles to play in providing public enlightenment, advocating for human and material resources, sound education, community mobilization, planning and delivery of long lasting reconciliation and ceasefire initiative effort between the two warring factions 
so as to allow for the return of internally displaced persons to their respective homes

\section{Conclusions and Recommendations}

Human rights and social justice are the philosophical foundations of social work practice. The uniqueness of social work practice is in the combination of some values, knowledge and skills, including the use of relationship as the basis of all interventions and respect for the client's choice and involvement. Social work profession strives to uplift the vulnerable and the oppressed people in the society, particularly the internally displaced persons in order to achieve the social inclusion and development (Midgley, 1997).

However, the paper made certain recommendations for the benefit of policy makers, stakeholders and change agents in order to address the problem of the internally displaced persons of the north-eastern states of Nigeria.

1. The government should strengthen its commitment to ensure that the rights of internally displaced persons are protected. This could be achieved by setting standards for addressing sexual and other forms of violence against the internally displaced persons so that perpetrators will be brought to book.

2. The law enforcement agents should endeavour to promptly address most problems faced by the displaced individuals. This will reduce periods of homelessness and minimize being exposed to sexual and other types of abuses.

3. The internally displaced persons should be included in the national HIV/AIDS and other health care programmes. The erroneous views that HIV/AIDS programmes are meant only for youths, uniform men and long distance drivers has inhibited various organizations from extending such service to the internally displaced persons.

4. Health Education with family planning and counselling services should be extended to the internally displaced persons to ensure that many more displaced persons have access to health care programmes.

5. The authorities at the local and state government levels should prevent internal displacement and promote durable solutions by building resilience, conflict resolution mechanism, civil status, contingency strategies, early warning systems and community intervention mechanisms.

6. Accountability measures should be put in place for violation of international law by state or non-state actors that can lead to displacement. The internally displaced persons should be encouraged to participate in reconciliation, peace processes and decide on durable solution that best suits their situation.
7. Every effort should be made to make sure that displaced persons can re-establish peaceful and productive life and do not remain in protracted displacement. The government, together with the development and humanitarian actors must work closely in developing durable solution strategies for the internally displaced persons by incorporating them into the national plans, ensuring access to employment and taking all preventive measures to end displacement.

\section{REFERENCES}

[1] Abdulazeez, M. (2016) The Boko Haram insurgency and internal displacement Presentation, (Nigerian Defence Academy) at the SEM, 20 June 2016

[2] Ahmad, N. (2009). Refugees: State Responsibility, Country of Origin and Human Rights. Asia-Pacific Journal on Human Rights \& The Law, 10 (2), 1-22. Doi: 10.1163/1388 19010X12647506166438

[3] Christensen, A. and Niels H. (2009). Forced Displacement: The Development Challenge, Conflict, Crime and Violence Issue Note. The World Bank, Washington, DC.

[4] Cohen, R. and Den, F. (2016). Masses in Flight: The Global Crises of Internal Displacement, Brooking Institute, Washington DC.

[5] Coate, R.A. \& Rosati, J. A. (1988). The Power of Human Needs in Society: L. Rienner Publishers, Colorado, USA

[6] Deng, F. (2007). "The guiding principles on internal displacement”. E/CN.4/1998//Add/. I, February 11. New York: United Nations.

[7] Dhemba, J. (2012). Fieldwork in Social Work Education and Training: Issues and Challenges in the Case of Eastern and Southern Africa. Social Work and Society: International Online Journal. 10 (1), 22- 35

[8] Ekpe, C.P. and Mamah, S.C. (1997). Social Work in Nigeria: A Colonial Heritage. Enugu: Unit Oriental Press.

[9] Falaju, J. (2005). NEMA moves to rehabilitate displaced persons in Adamawa. The Guardian newspaper.

[10] Hall, N. (1990). Social Work Training in Africa: A Fieldwork Manual. Harare, Journal of Social Development in Africa

[11] ICRC (2016). Internal Displacement in North East Nigeria: Operationalizing the Kampala Convention in Borno, Adamawa and Yobe States

[12] IFSW (1994). The Ethics of Social Work Principles and Standards, Bernes, Switzerland.

[13] Kellenberger, J. (2009). Special ICRC summit on refugees, returnees and IDPs in Africa, Kampala, Uganda. 
[14] Korn, D, (1988) Exodus within Borders: An introduction to crises of internal displacement, Brooking institutions, Washington DC.

[15] Krejcie, R.V \& Morgan, D.W (1970). Determining sample size for research activities. Educational and Psychological Measurement Vol. 30, pp. 607-610

[16] Midgley, J. (1997). Social Welfare in Global Context; SAGE Publications, Inc.; London, Thousand Oaks, New Delhi.

[17] Mohammed, F. K. (2017) the Causes and Consequences of Internal Displacement in Nigeria and Related Governance Challenges. Division Global Issues Stiftung Wissenschaft und Politik, German Institute for International and Security Affairs, Berlin.

[18] Oladeji, F, (2015) Humanitarian crisis and internally displaced persons (IDPs): addressing the plights of youth and women victims in Nigeria, Basic Research Journal of Social and Political Science ISSN 2465-7220 Vol. 3 (3) pp. 42-55 http//www.basicresearchjournals.org

[19] Okpeh, O.O. (2008). Inter - group Migrations, Conflicts and Displacement in central Nigeria (in Population Movements, Conflicts, and Displacement in Nigeria, (Ed.) T. Falola and O. OchayiOkpeh, Jr)

[20] Okoye, U.O. (2013). Trends and challenges of social work practice in Nigeria Accessed from: https://www.researchga te.net/publication/267868332_Trends_and_challenges_of_ social_work_practice_in_Nigeria Retrieved on May 30, 2016.

[21] Rider, E. (2012). Refugees, sexual violence, and armed conflict: The nuances between victims and agents. Wagadu: A Journal of Transnational Women's \& Gender Studies, 1072-92.

[22] The Internal Displacement Monitoring Center, IDMC (2016) NIGERIA: Multiple displacement crises overshadowed by Boko Haram, Norwegian Refugee Council

[23] UNHCR, "Protection Aspects of UNHCR Activities on Behalf of Internally Displaced Person”, EC/SCP787 (Geneva, 17 August 1994), p. 26

[24] United Nations (UN). 2006. Larger freedom: Towards development, security and human rights for all. New York: United Nations Department of Public Information 